\title{
Comparison of Efficacy of Ondansetron versus Granisetron for the Control of Postoperative Nausea and Vomiting In Patients Undergoing Laparoscopic Cholecystectomy
}

\author{
A.Ramya Parameswari ${ }^{1}$, Sivakumar Gopalswamy ${ }^{2}$ \\ ${ }^{1}$ Department of Anesthesiology, North Middlesex Hospital, London. UK. \\ ${ }^{2}$ Department of Surgery, Royal Cornwall hospital. Truro. UK.
}

\begin{abstract}
Postoperative nausea and vomiting (PONV) not only increases patient discomfort as for some of the patients, PONV is even more distressing than post operative pain, but also adds to hospital expenditure (increased hospital stay, antiemetics) and complications related to vomiting (dehydration, electrolyte disturbances, pulmonary aspiration and rarely esophageal rupture). AIM: This study is to compare the efficacy of ondansetron hydrochloride $(80 \mu \mathrm{g} / \mathrm{kg})$ versus granisetron hydrochloride $(20 \mu \mathrm{g} / \mathrm{kg})$ for the control of postoperative nausea and vomiting in patients undergoing laparoscopic cholecystectomy. METHODS: One hundred and forty consecutive adult patients scheduled for elective laparoscopic cholecystectomy were randomized into two groups: group $O$ ondansetron group $(n=70)$ and group $G$ Granisetron ( $n$ $=70)$. Randomization was done using sealed envelope technique. A standard protocol was used in all the patients. The postoperative nausea and vomiting scoring was started immediate post-extubation. The patients were monitored in the recovery unit for the initial two hours. During that period the incidence of nausea and vomiting were recorded every 15 minutes. The nausea and vomiting scoring was continued eighth hourly for the next 24 hours. RESULTS: It was observed that 6 patients from group $O$ and 3 patients from group $G$ had nausea at extubation. The incidence of nausea gradually decreased over the next 24 hours, in both the groups. With regard to the incidence of vomiting, there was a gradual decrease in the incidence with time, in both our study groups. At extubation, 2 patients from group $O$ and 1 patient from group $G$ had one bout of vomiting. But 2 hours post extubation, none of the patients from both the groups had vomiting. On overall comparison, $37 \%$ of ondansetron hydrochloride group had nausea compared to $23 \%$ in the granisetron hydrochloride group. And $16 \%$ from the ondansetron hydrochloride group had vomiting in compasison to $3 \%$ in the granisetron hydrochloride group. Thus, based on our study we conclude that, Ondansetron $(80 \mu \mathrm{g} / \mathrm{kg})$ is as efficacious as Granisetron $(20 \mu \mathrm{g} / \mathrm{kg})$ for the control of postoperative nausea and vomiting in patients coming for laparoscopic cholecystectomy.
\end{abstract}

Keywords: Postoperative nausea and vomiting, cholecystectomy, ondansetron, granisetron

\section{Introduction}

The most common and distressing symptoms, which follow anaesthesia and surgery, are pain and emesis. Postoperative nausea and vomiting (PONV) not only increases patient discomfort as for some of the patients, PONV is even more distressing than post operative pain, but also adds to hospital expenditure (increased hospital stay, antiemetics) and complications related to vomiting (dehydration, electrolyte disturbances, pulmonary aspiration and rarely esophageal rupture). During ether era, reported incidence of PONV was as high as $75-80 \%$. One of the first extensive descriptions of this phenomenon was by Sir John Snow in 1848, within 18 months of chloroform introduction in anaesthesia ${ }^{1}$. There have been a volley of systemic reviews in the world literature on $\mathrm{PONV}^{2,3,4}$. However there is no consensus on the specific treatment of PONV. Intractable PONV is the most frequent anaesthetic related cause for unexpected hospital admission of surgical out patients ${ }^{5}$

There are a number of factors influencing the occurrence of PONV which includes patient factors age, gender, obesity, anxiety, history of motion sickness or previous PONV and gastroparesis, operative procedures, anesthetic techniques, drugs for general anesthesia, regional anesthesia and monitored anesthesia care and postoperative factors -pain, dizziness, ambulation, oral in-take and opioids.

A large number of drugs are available for prevention of PONV, of which 5-HT3 receptor antagonists have occupied an important position because of their better efficacy minimal side effects.

There are three major components of vomit reflex: emetic detectors, integrative mechanisms and motor output. The main sensors of somatic stimuli are located in the gut and chemo-receptor trigger zone (CTZ). The emetic stimuli in gut are detected by two types of vagal afferent fibres. 
Definitions $^{6}$

Nausea: It is an unpleasant sensation referred to as a desire to vomit, not associated with expulsive muscular movement.

Retching: When no stomach contents are expelled even with expulsive muscular efforts.

Vomiting: It is the forceful expulsion of even a small amount of upper gastrointestinal contents through the mouth.

\section{Materials}

One hundred and forty consecutive adult patients scheduled for elective laparoscopic cholecystectomy were included in this randomized, prospective study. They were randomized into two groups: group $\mathrm{O}$ ondansetron group $(n=70)$ and group $G$ Granisetron $(n=70)$. Randomization was done using sealed envelope technique. Institutional ethical committee clearance was obtained.

\section{Inclusion criteria:}

Age group - 25 to 70 years

Sex - equal number of male and female

ASA I and II

Posted for Laparoscopic cholecystectomy

\section{Exclusion criteria:}

History of motion sickness

History of renal, hepatic and cardiac disorders

Preoperative nausea and vomiting

Anti emetic medications during previous $24 \mathrm{hrs}$

Previous history of postoperative nausea and vomiting

Overweight (BMI>30)

Patients on cancer chemotherapeutic agents

Patients on preoperative opioids

Patients with gall bladder malignancy

Patients presenting with acute symptoms

Menstruating females and pregnant females

Patients with gastro esophageal reflux disorders

\section{Methods}

Preoperative assessment and evaluation was done for all the patients. On arrival into the theatre, peripheral intravenous access was established. All baseline values of monitoring were noted. Anaesthesia was induced with

Injection Fentanyl $(2 \mu \mathrm{g} / \mathrm{kg})$,

Injection Lidocaine $2 \%$ preservative free $40 \mathrm{mg}$

Injection Propofol $(2 \mathrm{mg} / \mathrm{kg})$

Injection ondansetron $(80 \mu \mathrm{g} / \mathrm{kg})$ or $\quad$ injection granisetron $(20 \mu \mathrm{g} / \mathrm{kg})$

Anesthesia was maintained with $66 \%$ Nitrous oxide, 33\% Oxygen, and Desflurane (3\%).Analgesia was supplemented with IV Diclofenac Sodium (75mg) infusion intraoperatively, and local infiltration with Bupivacaine $0.5 \%$ over intended port sites, before incision. The patients were ventilated in volume control mode (Aestiva 5, Datex Ohmeda) to achieve target $\mathrm{EtCo}_{2}$ of 30-35 mm Hg. After intubation an orogastric tube was inserted. At the end of the surgery patients were reversed with Neostigmine $(0.04 \mathrm{mg} / \mathrm{kg})$ and Glycopyrrolate $(0.01 \mathrm{mg} / \mathrm{kg})$ and extubated. The postoperative nausea and vomiting scoring was done immediate post-extubation.

The scoring was done as follows:

0 -no nausea or vomiting

1 -nausea

2 -retching only

3 -vomiting.

The patients who had a score of $2 / 3$ and above anytime during the observation period were treated with a relief antiemetic -Injection.ondansetron $4 \mathrm{mg}$ intravenously.

Patients with pain were given Injection Diclofenac 75mg intramuscularly.

The patients were monitored in the recovery unit for the initial two hours. During that period the incidence of nausea and vomiting were recorded every 15 minutes. The nausea and vomiting scoring was continued eighth hourly for the next 24 hours. 


\section{Statistical Analysis}

All categorical data's are presented in the form of frequency with percentages and its analyzed by chi-square and Fisher exat test. Continuous data are represented in mean with standard deviation and analysed with the help of Independent t-test. All the analysis were done by using SPSS 14.0 version. P value less than 0.05 considered as significant.

The groups were comparable in terms of demographic data.

One patient from the Granisetron group was excluded from the study based on exclusion criteria.

\begin{tabular}{|c|c|c|c|c|}
\hline Duration & Symptoms & Ondansetron & Granisetron & $\mathrm{P}$ value \\
\hline \multirow{2}{*}{$\mathrm{O} \min$} & Nausea & 6 & 3 & \multirow{2}{*}{0.764} \\
\hline & Vomiting & 2 & 1 & \\
\hline \multirow{2}{*}{15 min. } & Nausea & 10 & 6 & \multirow{2}{*}{0.561} \\
\hline & Vomiting & 3 & 1 & \\
\hline \multirow{2}{*}{$30 \mathrm{~min}}$. & Nausea & 11 & 5 & \multirow{2}{*}{0.657} \\
\hline & Vomiting & 3 & 1 & \\
\hline \multirow{2}{*}{45 min. } & Nausea & 10 & 5 & \multirow[b]{2}{*}{0.258} \\
\hline & Vomiting & 4 & 0 & \\
\hline \multirow{2}{*}{$60 \mathrm{~min}$} & Nausea & 13 & 6 & \multirow{2}{*}{0.648} \\
\hline & Vomiting & 3 & 1 & \\
\hline \multirow{2}{*}{75 min. } & Nausea & 16 & 7 & \multirow{2}{*}{0.708} \\
\hline & Vomiting & 1 & 0 & \\
\hline \multirow{2}{*}{90 min. } & Nausea & 10 & 6 & \multirow{2}{*}{0.431} \\
\hline & Vomiting & 2 & 0 & \\
\hline \multirow{2}{*}{$105 \mathrm{~min}}$. & Nausea & 8 & 7 & \multirow{2}{*}{0.331} \\
\hline & Vomiting & 2 & 0 & \\
\hline \multirow{2}{*}{$120 \mathrm{~min}}$. & Nausea & 9 & 6 & \multirow{2}{*}{0.404} \\
\hline & Vomiting & 2 & 0 & \\
\hline \multirow{2}{*}{8 hours } & Nausea & 6 & 6 & \multirow[b]{2}{*}{ - } \\
\hline & Vomiting & 0 & 0 & \\
\hline \multirow{2}{*}{16 hours } & Nausea & 4 & 4 & \multirow[b]{2}{*}{-} \\
\hline & Vomiting & 0 & 0 & \\
\hline \multirow{2}{*}{24 hours } & Nausea & 5 & 3 & \multirow{2}{*}{ - } \\
\hline & Vomiting & 0 & 0 & \\
\hline
\end{tabular}

At extubation, 6 patients from group $\mathrm{O}$ and 3 patients from group $\mathrm{G}$ had nausea. The number of patients with nausea increased gradually from immediate post extubation to upto 75 minutes post extubation in both the groups, reaching a maximum of 16 in ondansetron group and 7 in granisetron group. However on comparison between the groups during the corresponding period, the difference was statistically insignificant.

At extubation the incidence of vomiting in the ondansetron hydrochloride group was $2 / 70$ and in the granisetron hydrochloride group was $1 / 69$. There was a gradual decrease in the incidence of vomiting with time in both the groups.

None of the patients in the ondansetron hydrochloride group had vomiting after 120 minutes whereas in the granisetron hydrochloride group , none of the patient had vomiting after 60 minutes post extubation.

\section{Complications}

\begin{tabular}{|l|l|l|l|}
\hline Complication & Ondansetron & Granisetron & P Value \\
\hline Nausea & 26 & 16 & \multirow{2}{*}{0.116} \\
\hline Vomiting & 11 & 2 & \\
\hline
\end{tabular}

On overall comparison, it was found that $26 / 70$ had nausea in the ondansetron hydrochloride group compared to 16/69 in the granisetron hydrochloride group. 11/70 had vomiting in the ondansetron hydrochloride group compared to 2/69in the granisetron hydrochloride group.

$37 \%$ of ondansetron hydrochloride group had nausea compared to $23 \%$ in the granisetron hydrochloride group. And 16\% from the ondansetron hydrochloride group had vomiting in compasison to $3 \%$ in the granisetron hydrochloride group. 


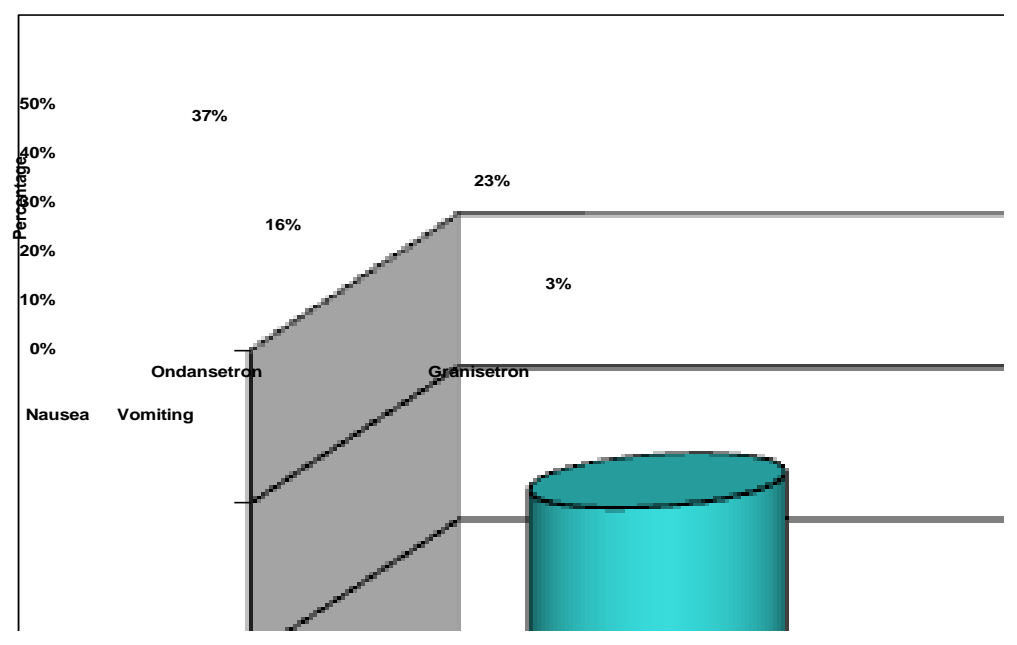

\section{Discussion}

PONV is amongst the most common complications following anaesthesia and surgery with a selectively high incidence after laparoscopic cholecystectomy.

Among surgeries, laparoscopic surgeries, ENT, breast, gynaecological surgeries are a few, which are associated with an increased incidence of postoperative nausea and vomiting. Hence we decided to conduct this study on a population coming for laparoscopic surgeries. However, different laparoscopic surgeries are associated with different incidences of postoperative nausea and vomiting. Hence to avoid biasing, our study was confined to patients coming for laparoscopic cholecystectomy. The etiology behind PONV following laparoscopic cholecystectomy is complex and multifactorial and is dependent on variety of factors including patient demographics, type of surgery, anaesthetic technique and postoperative care. Patient related factors are age, sex, obesity, a history of motion sickness, menstruation and history of $\mathrm{PONV}^{7}$. In our clinical trial however, the treatment groups were similar with respect to patient demographics, operative management and patient related factors. Duration of surgery and agents used for anaesthesia were also standardised. Similarly, the consumption of opiate analgesics was closely monitored to ensure that differences between the groups in opioid consumption should not be a confounding factor.

After the Food and Drug Administration "black box" warning on droperidol based on concerns about prolonged QTc interval associated with use of the doses specified in Management of Postoperative Nausea and Vomiting, droperidol use has declined dramatically.

The introduction of 5HT3 (serotonin) receptor antagonists in $1991^{8}$ has heralded a major advance in treatment of PONV because of absence of adverse effects that were observed with commonly used antiemetic drugs. The 5HT3 receptor antagonists produce no sedation, no extra pyramidal symptoms or adverse effects on vital signs and do not interact with other anaesthetic agents. Dose of ondansetron hydrochloride and granisetron hydrochloride were based on body weight only in pediatric patients. However for standardization purposes their dose was based on body weight in our study in adults also. Hence, this study was conducted to compare the efficacy of ondansetron at a dose of $80 \mu \mathrm{g} / \mathrm{kg}$ with granisetron at a dose of $20 \mu \mathrm{g} / \mathrm{kg}$ for the control of PONV. A lower dose of granisetron was chosen based on previous studies ${ }^{9}$ which proved its efficacy even at a lower dose. In our study, the study drug was administered to all the patients at induction of anaesthesia. All patients were monitored over the next 24 hours for evidence of postoperative nausea and vomiting. The patients were assessed every 15 minutes for the initial 2 hours and then assessed every 8 hours for 24 hours.

With regard to the incidence of vomiting,there was a gradual decrease in the incidence with time, in both our study groups. At extubation ,2 patients from group $\mathrm{O}$ and 1 patient from group $\mathrm{G}$ had one bout of vomiting.

On comparison for the entire 24 hour period, it was observed that $37 \%$ of patients from group $\mathrm{O}$ and $23 \%$ of group $\mathrm{G}$; and $16 \%$ of group $\mathrm{O}$ and $3 \%$ of group $\mathrm{G}$ had vomiting. Though an observable difference was noted between the two groups, it was however found to be statistically insignificant. Thus, ondansetron hydrochloride $(80 \mathrm{mcg} / \mathrm{kg})$ is as efficacious as granisetron hydrochloride $(20 \mathrm{mcg} / \mathrm{kg})$.

However, the drawback with our study was that multimodal approach to postoperative nausea and vomiting was not followed. Eventhough propofol was used for induction and the patients were well hydrated, the influence of these factors on the incidence of postoperative nausea and vomiting were not studied. When used in combination with other antiemetics, a still lower dose of ondansetron hydrochloride and granisetron hydrochloride could have been used. In terms of cost benefit effects, granisetron hydrochloride is more economical than ondansetron hydrochloride at the dose used in our study. However this comparison was not made in our study. 
Thus, the results of our study indicate that ondansetron hydrochloride is as efficacious as granisetron hydrochloride for the control of postoperative nausea and vomiting in patients coming for laparoscopic surgery.

\section{Conclusion}

One hundred and forty patients undergoing laparoscopic cholecystectomy were included in a prospective randomized control study to compare the efficacy of ondansetron $(80 \mu \mathrm{g} / \mathrm{kg}$ ) with granisetron $(20 \mu \mathrm{g} / \mathrm{kg})$ for the control of postoperative nausea and vomiting.

The number of patients who had nausea gradually increased from immediate post-extubation period to upto 75 minutes when the maximum number was noted in both the groups. The incidence of nausea then decreased gradually over the next 24 hours and was comparable between the two groups. The difference was however statistically insignificant.

However the incidence of vomiting was much lower in both the groups and showed a decrease with time. No incidence of nausea was noted in the ondansetron group after 2 hours post extubation and after 1 hour post extubation in the granisetron group. No significant side effect was noted in either of the groups. Thus, based on our study we conclude that, Ondansetron $(80 \mu \mathrm{g} / \mathrm{kg})$ is as efficacious as Granisetron $(20 \mu \mathrm{g} / \mathrm{kg})$ for the control of postoperative nausea and vomiting in patients coming for laparoscopic cholecystectomy.

Conflict of interest: none to declare.

\section{Bibliography}

[1]. Andrew PL, Physiology of nausea and vomiting; Br J Anaesth1992; 69: 2-19.

[2]. McKay WP, Yip RW. Distribution of randomised controlled trials of drugs for postoperative nausea and vomiting. Can J Anaesth 2000; 47(5): 421-26.

[3]. Watcha MF. Postoperative nausea and emesis : Anesth Clin North America 2002; 20(3): 471-84

[4]. Kazemi-Kjellberg F, Henzi I, Tramer MR. Treatment of established postoperative nausea and vomiting. A quantitative systemic review. BMC Anaesthesiol 2001; 1(1): 2 .

[5]. Gold BS, Kitz DS, Lecky JH, Neuhans JM. Unanticipated admission to hospital following ambulatory surgery. JSMA1989; 262: 3008-10.

[6]. Saeeda Islam P. N. Jain postoperative nausea and vomiting, a review article: Indian journal of anaesthesia2004;48(4):253-258

[7]. Sarkar M, Sarkar A, Dewoolkar L, Charan S. Comparative Study of single dose intravenous ondansetron and metoclopramide as a premedication for prevention of post operative nausea and vomiting in obstetrical laparoscopic surgery under general anaesthesia. Internet J Anesthesiology 2007; 13: 2.

[8]. Sneader W. Drug Discovery: A History ( John Wiley and Sons, Ltd.: West Sussex, England, 2005. pp. 217 -19)

[9]. Gan TJ, Coop A, Philip BK. A randomized, double-blind study of granisetron plus dexamethasone versus ondansetron plus dexamethasone to prevent postoperative nausea and vomiting in patients undergoing abdominal hysterectomy. Anesth Analg. 2006 Aug;103(2):510-1; author reply 511 